2017-09-04

\title{
Tribological properties of nanoclay reinforced polyimide nanocomposite coatings for alloy steels
}

\section{MENG, MAOZHOU}

http://hdl.handle.net/10026.1/12597

\author{
10.1111/ijac. 12747 \\ International Journal of Applied Ceramic Technology \\ Wiley
}

All content in PEARL is protected by copyright law. Author manuscripts are made available in accordance with publisher policies. Please cite only the published version using the details provided on the item record or document. In the absence of an open licence (e.g. Creative Commons), permissions for further reuse of content should be sought from the publisher or author. 


\title{
Tribological Properties of Nanoclay Reinforced Polyimide Nanocomposite Coatings for Alloy Steels
}

\author{
Maozhou Meng, Huirong Le* \\ Department of Mechanical Engineering and Built Environment, College of Engineering and Technology, \\ University of Derby, Derby, United Kingdom \\ Email: h.le@derby.ac.uk
}

\begin{abstract}
A new process was developed to deposit uniform Montmorillonite nanoclay reinforced polyimide nanocomposite coating on alloy steels. The nanoclay particles were successfully dispersed in $\mathrm{N}, \mathrm{N}$-Dimethylacetamide using a combination of magnetic stirring, soaking and ultrasonic agitation. It was found that the uniform and crack free coating can be achieved. The tribological tests indicated that the nanocomposite coating has good adhesion to alloy steels, good load carrying capacity, relatively low friction and wear. This nanocomposite is a promising material for some offshore, aerospace and automotive structures that are subjected to sliding contact in corrosive environment.
\end{abstract}

Keywords: Polyimide; Nanocomposites; Coating; Nanoclay 


\section{Introduction}

The synthesis of aromatic polyimides can be tracked back to 1908 [18], later the properties of polyimide have been improved significantly by a two-stage polycondensation of pyromellitic dianhydride with diamines so that leading to mass production since 1955 [14]. Polyimide is one of the strongest plastic materials with excellent heat resistance, chemical stability, wear/erosion resistance and superior electrical properties [21, 28]. Polyimide parts are not affected by many commonly used solvents and oils, such as hydrocarbons and alcohols, which indicates that polyimide can be an excellent coating material at elevated temperature and/or in weathering conditions, such as microelectronics packaging $[6,25,10,16]$, offshore structures $[30,29,2]$ and aerospace components $[4,27,17]$.

Substrate materials coated by polyimide benefit from its excellent properties, however, there is a need to reduce the thermal expansion and improve permeability and wear resistance of monolithic polyimide coating. The coefficient of thermal expansion of polyimide is related to the linearity of polymer molecular skeletons [5], thus many researchers have attempted to modify the polymer backbone in order to reduce the coefficient of thermal expansion, such as incorporating fluorine into the polymer backbone [7]. However, the incorporation of fluorine into polyimide degrades the mechanical properties of polyimide significantly [8]. Compared with other types of polymers, polyimide absorb much more moisture, for example the typical saturated moisture absorption of polyimide can be as high as $4.4 \%$, which is considerably higher than epoxy $(1.5 \%)$ and PEEK $(0.5 \%)$ [15]. Hygrothermal expansion due to moisture absorption may be detrimental if combined with thermal expansion which induces initial stresses and degrades mechanical properties of the coating. This is particularly critical for those applications in humidity environment such as offshore structures, automotive exhaust pipe and aeroengine components.

It is possible to reduce both the coefficient of thermal expansion and permeability coefficient by adding ceramic particles into polyimide, due to their low coefficient of thermal expansion and high gas barrier properties; therefore, there has been significant interest in ceramic nanoparticle reinforced 
polyimide composites in the last two decades. Nanoclay has been widely used as a reinforcement material for polymeric materials. It can be intercalated by surfactants to become nano sheets due to its layered structure. Okada et al. successfully intercalated montmorillonite with ammonium salt of 12-aminodecanoic acid and dispersed into nylon-6 matrix [19], later Yano et al. applied the same technique for polyimide and reported that they successfully reduced the coefficient of thermal expansion by around $50 \%$ and the permeability coefficient by around $80 \%$ [31]. Khayankarn et al. used propane dianhydride as a precursor to intercalate dodecylamine- montmorillonite into polyimide matrix and successfully reduced the gas permeability coefficient by $50 \%$, and in the meantime improved the adhesion strength between coating film and substrate [11]. Wang et al. reported a centrifugal deposition process to fabricate $\mathrm{Ca}^{2+}$-type montmorillonite-polyimide nanocomposite coating with a nacre-like layered structure which has superior strength and hardness [26].

These polymer-based nanocomposite materials are promising candidates for surface coatings for a wide range of applications due to their improved corrosion and wear resistance compared to monolithic polymer coatings. One potential application is in tubular connections which require low coefficient of friction and high wear resistance at extremely high contact pressure. The authors have recently developed a CNT reinforced epoxy composites for offshore pipelines [1, 12, 13]. The materials exhibit good anti-galling resistance, however the corrosion resistance is not sufficient for heavily loaded premium connections due to the surface porosity as a results of the difficulty in dispersion of carbon nanotubes. The properties of interest for this application include friction and wear of the material under sliding contact with steel. The main challenge in adding ceramic nanoparticles to a polymer material is dispersion of nanoparticles during the process. One method is to mix ceramic nanoparticles with powder of polyimide followed by thermal curing as described by $[7,20,23]$, while the other method is to disperse ceramic nanoparticles in precursors of polyimide as reported by $[24,11,3]$. It has been shown that the latter leads to a much thorough mixing at nanoscale. In this paper, a liquid dispersion process was developed to fabricate nanoclay-polyimide composite materials. The suspension was deposited on chromium steel substrate and then dried and cured by 
thermal imidization in oven. The tribological properties of the nanocomposites were examined using a cross cylinder sliding test rig developed by the author and his collaborators $[12,22,13]$.

\section{Experimental Methods}

\subsection{Preparation of Coupons}

The substrate coupons were made of high chrome alloy steel, which were cut from a circumferential short pipe by electrical discharge machining (EDM) as shown in Figure 1. The dimension of both short pipe and the small coupons are also shown in the figure.

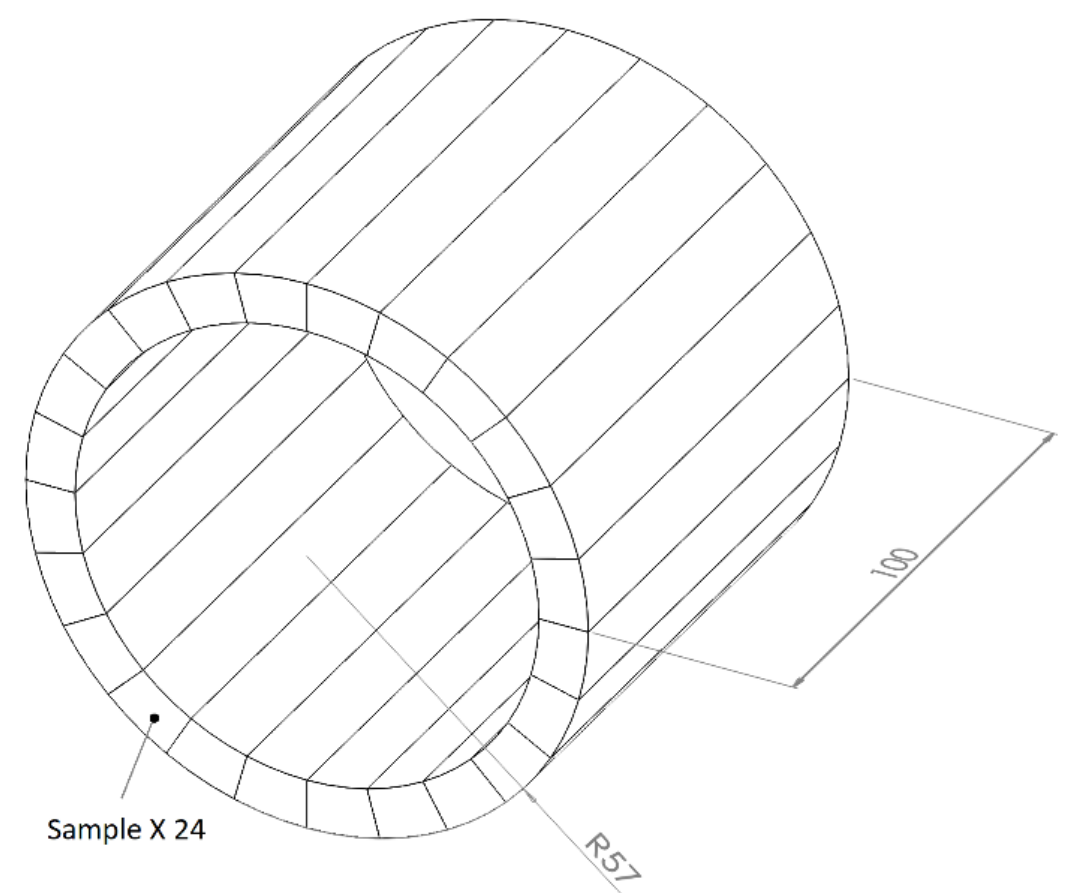

Figure 1. Machining of coupons from a short pipe

The coupons are subjected to sand blasting under a pressure of 60bar for duration of 3-5 minutes. The shot blasting media consisted of alumina beads around 100 microns in diameter. Figure 2 shows a typical surface image after the shot blasting. The surface morphology, i.e. surface roughness was measured using 3D surface profile meter (Olympus Inc.) and five measurements were taken from each sample. The samples following blasting has an average surface roughness of $\mathrm{Ra}=1.89 \mu \mathrm{m}$ and $\mathrm{Rq}=2.46 \mu \mathrm{m}$ 


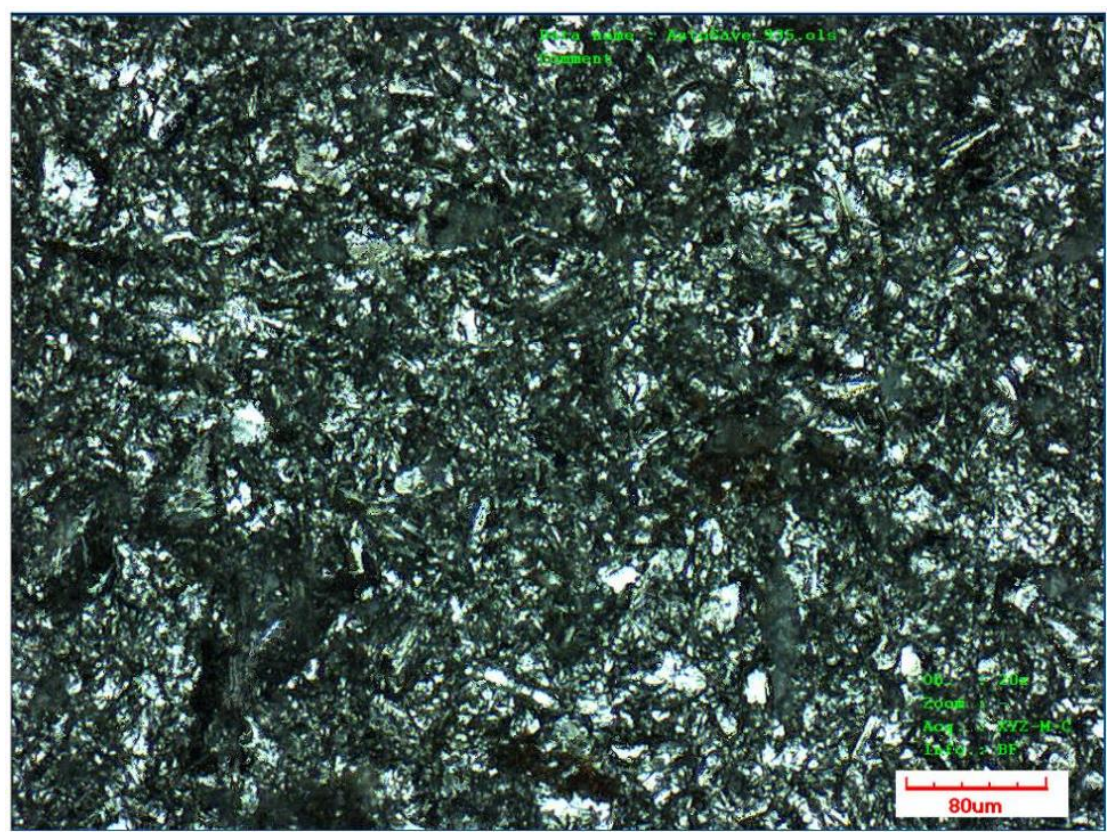

Figure 2. Shot blasted surface by optical microscope, $\mathrm{Ra}=1.89 \mu \mathrm{m}, \mathrm{Rq}=2.46 \mu \mathrm{m}$

\subsection{Preparation of nanoclay composite}

All the substrates were cleaned with a paint brush, mutton cloth, and acetone before coating, to remove contaminants such as oil, grease, moisture, and dust. The Montmorillonite (MMT) clay platelets with 25 - 30 wt. \% trimethyl stearyl ammonium (purchased from Sigma-Aldrich UK) was used in this study. Figure 3 shows a typical scanning electron microscopic (JEOL 7100, Japan) image of as-received MMT clay. The particle size of the clay varies from $1 \mu \mathrm{m}$ up to $3 \mu \mathrm{m}$.

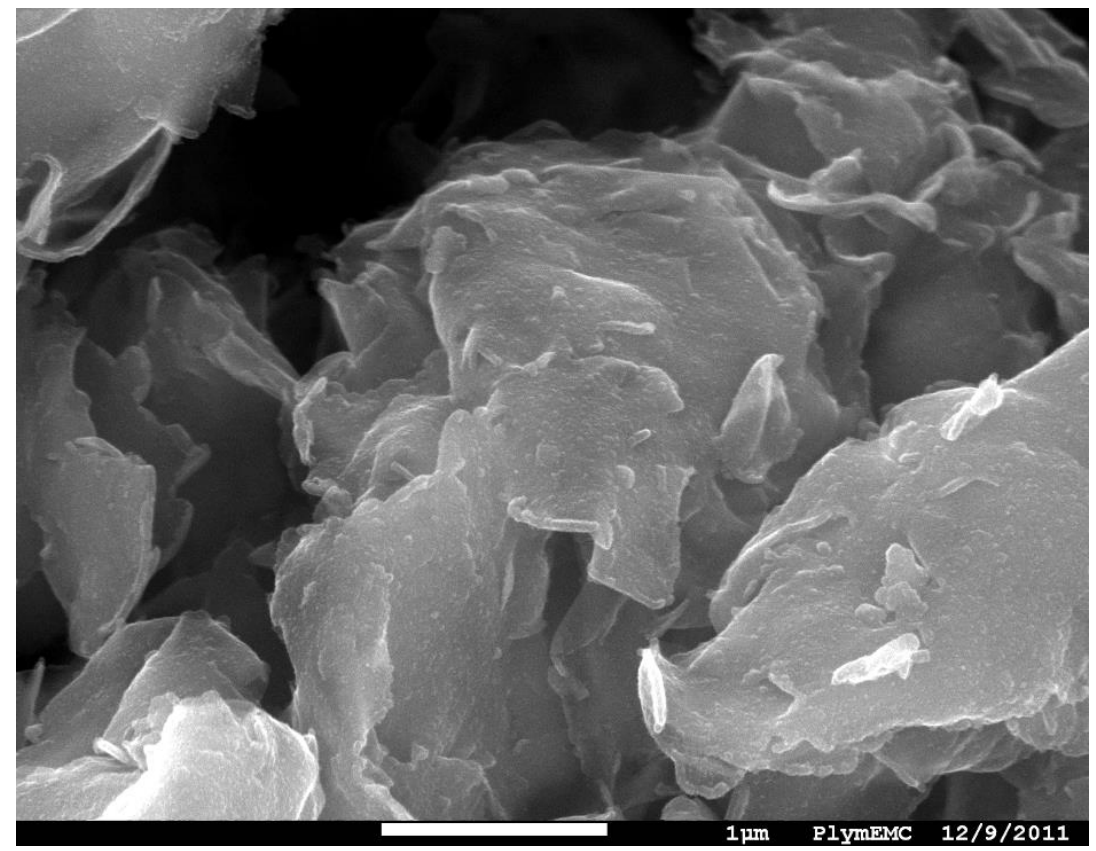

Figure 3. Montmorillonite platelets As-received 
The MMT particles were dried at $100^{\circ} \mathrm{C}$ in a beaker for one hour, and then mixed with $\mathrm{N}, \mathrm{N}-$ Dimethylacetamide (DMAc) solvent (purchased from Sigma-Aldrich, UK) at a weight ratio of 1:6. The MMT suspension was stirred on a magnetic stirrer for 15 minutes at $30-40^{\circ} \mathrm{C}$, after that it was soaked for about 12 hours at room temperature. Magnetic stirring process was carried out again for the soaked MMT solution for 5 minutes and then the MMT suspension was placed in an ultrasonic bath for 30 minutes to divide (disperse) the MMT clay platelets in solution. The dispersed MMT suspension was then placed on the magnetic stirrer and mixed with 4, 4-Oxydianiline (ODA at MMT to ODA ratio of $1: 1$ ). This suspension was stirred at $30-40^{\circ} \mathrm{C}$ by $200 \mathrm{rpm}$ for about 3 hours in a beaker, labelled as Beaker A.

The precursor was made separately in another beaker, labelled as Beaker B, in which pyromellitic dianhydride (PMDA) was mixed with DMAc solvent at a ratio of 1:5.5. The solution was stirred on a magnetic stirrer for 3 hours at $30-50^{\circ} \mathrm{C}$ by $200 \mathrm{rpm}$. The solution in Beaker B was slowly transferred to beaker A at a rate of $30 \mathrm{ml} / \mathrm{min}$, whilst the mixture in Beaker A was stirred at $30-40^{\circ} \mathrm{C}$ by $300 \mathrm{rpm}$ on the magnetic stirrer. Finally, the clay/polymer composite suspension was placed into refrigeration for further coating process. This process (production of clay polymer composite solution) is shown in Figure 4 in graphical form.

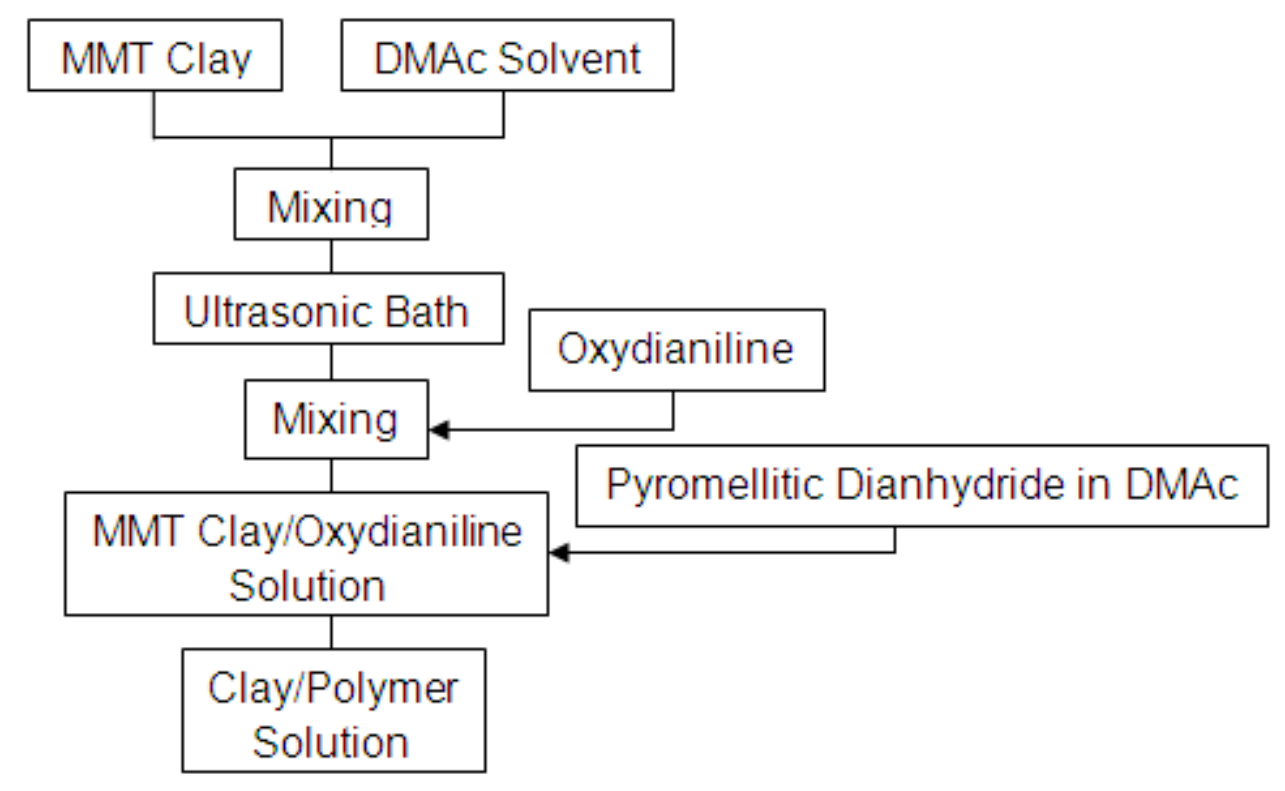

Figure 4. Production of Clay/Polyimide composite suspension 


\subsection{Clay/Polyimide Coating on Coupons}

The substrate coupons were dipped into a bath of clay polyimide composite suspension. The excess coating solution on substrate coupon was brushed off with a paint brush. The coupons were then placed horizontally in an oven for 24 hours and the temperature was set at $40^{\circ} \mathrm{C}$ in order to remove the DMAc solvent. The clay/polyimide composite coating on substrate coupons were then cured in stepwise for 30 minutes at $100^{\circ} \mathrm{C}, 150^{\circ} \mathrm{C}, 200^{\circ} \mathrm{C}$ respectively and finally 60 minutes at $250^{\circ} \mathrm{C}$. The microstructure of this nanoclay reinforced polyimide nanocomposite coatings was examined by an SEM. It is expected that the polyimidization would be complete under these conditions but will be discussed in Section 3.

\subsection{Adhesion and Tribological Testing}

The adhesion strength of coatings was measured by a digital push-off adhesion tester (Elcometer 508, with capacity of $25 \mathrm{MPa}$ ), and the acrylic adhesive was used as glue, bonding the dolly and coating together, as shown in Figure 5. This is instant and cured versatile glue, which can be used to bond polymer to metal. In order to get the strongest bonding properties, the bonded parts were left for 24 hours before carrying out the adhesion test.

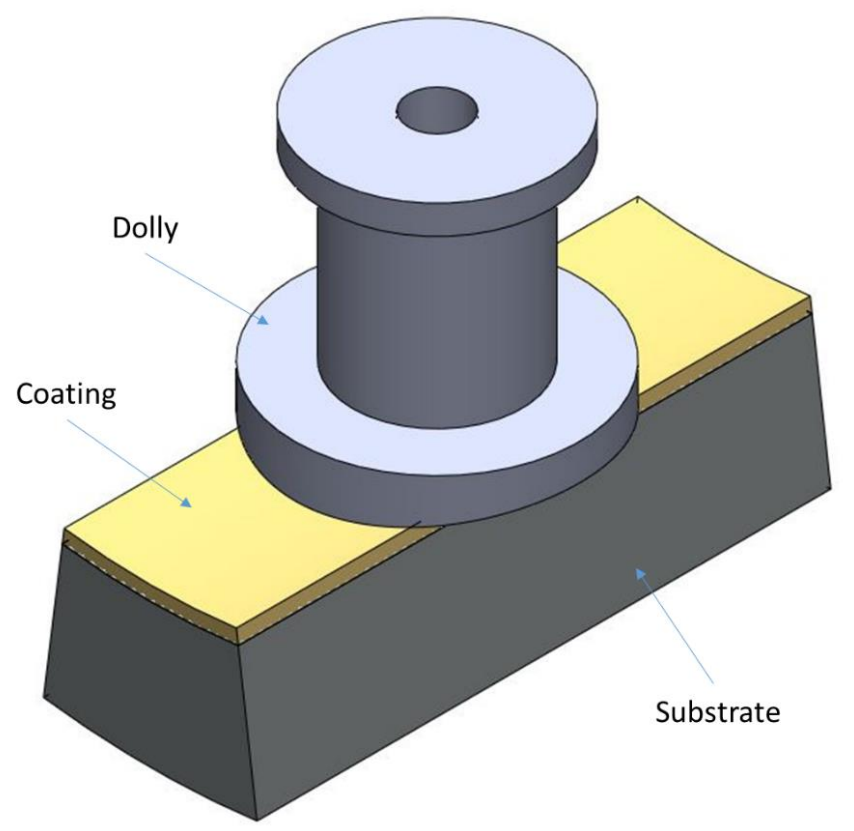

Figure 5. Schematic of the hydraulic pull-off adhesion tester 
Hydraulic force was applied on a small cylindrical pin which went through the central hole of the dolly until the coatings, and relative movement between the pin and dolly pushed the coatings out of the dolly. There is curvature on the coupon surface, therefore the dolly was manufactured to fit the coupon surface. It should be noted that the contact area between dolly and coatings was approximate $81 \%$ of the dolly's surface area because the width of the coupon is smaller than the diameter of the dolly, thus adhesion strength was adjusted by the reading of adhesion tester.

A cross-cylinder friction test rig was developed to simulate the contact regimes in a tubular connection, as shown in Figure 6. The test rig was designed so that the two coupons can be mounted on two holders perpendicularly, and both the convex surfaces were in contact. The top holder was fixed horizontally, however the bottom holder was mounted on a stage which had an ascent adjusted by a micrometer screw, in a range of $0-5^{\circ}$. A small initial normal force was applied between the top and bottom coupons, and this normal force was increasing while the stage was moved by a linear motor. Tangential and normal forces were recorded continuously by a computer, so that the coefficient of friction can be obtained.

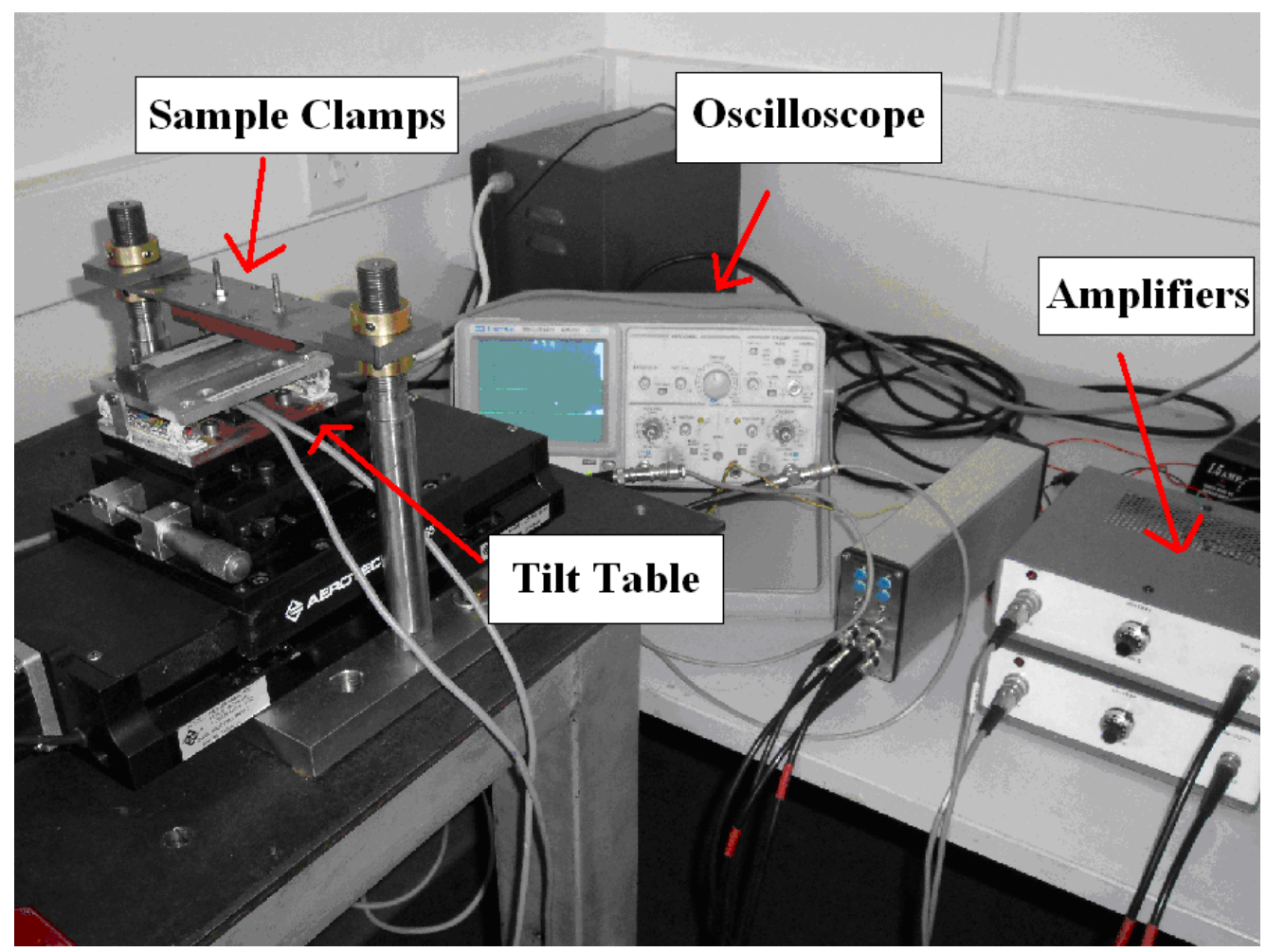

Figure 6 Reciprocal sliding friction and galling tester 
The theory of contact between elastic bodies (Hertz model) can be used to evaluate the contact stresses. Contact between two crossed cylinders of equal radius $\mathrm{R}$, the maximum and average contact pressure $\mathrm{P}_{0}, \mathrm{P}_{\mathrm{a}}$ are given by [9]

$$
\begin{aligned}
& p_{0}=\frac{1}{\pi}\left(\frac{6 F E^{* 2}}{R^{2}}\right)^{1 / 3} \\
& p_{a}=\frac{2}{3} p_{0} \\
& E^{*}=\frac{E}{2\left(1-v^{2}\right)}
\end{aligned}
$$

where $\mathrm{F}$ is the normal force, $\mathrm{E}$ and $v$ are the Young's modulus and Poisson's ratio respectively. As a benchmark, the average contact pressure for bare steel on steel contact under a normal force of $400 \mathrm{~N}$ is roughly $425 \mathrm{MPa}$. It should be noted that only the bottom coupons in the test rig was coated, and the top coupon was treated by shot peening. Therefore, the contact stress will be lower than this estimation due to the lower modulus of the composite. The test will cause wear or even damage to the surface of the samples. The surfaces of both samples were observed under digital optical microscope and scanning electron microscope.

\section{Results and Discussions}

\subsection{Micro/Nanostructure}

High resolution SEM (JEOL 7001) was used to assess the MMT clay platelet's morphology, surface characteristics of pure polyimide, polyimide/MMT clay, and the dispersion of MMT clay platelets in polyimide. Figure 7(a) shows the nanostructure of monolithic polyimide coating. The cuboid structure confirms that the material was crystalized polyimide. Figure 7(b) shows the nanostructure of the nanoclay reinforced polyimide composites. It can be seen that the nanoclay particles are very well dispersed within the polyimide matrix, however, there are also some matrix rich regions, which were found in composite coating. However, no obvious orientation was observed of nanoclay sheets, which is consistent with the brushed coating process. 

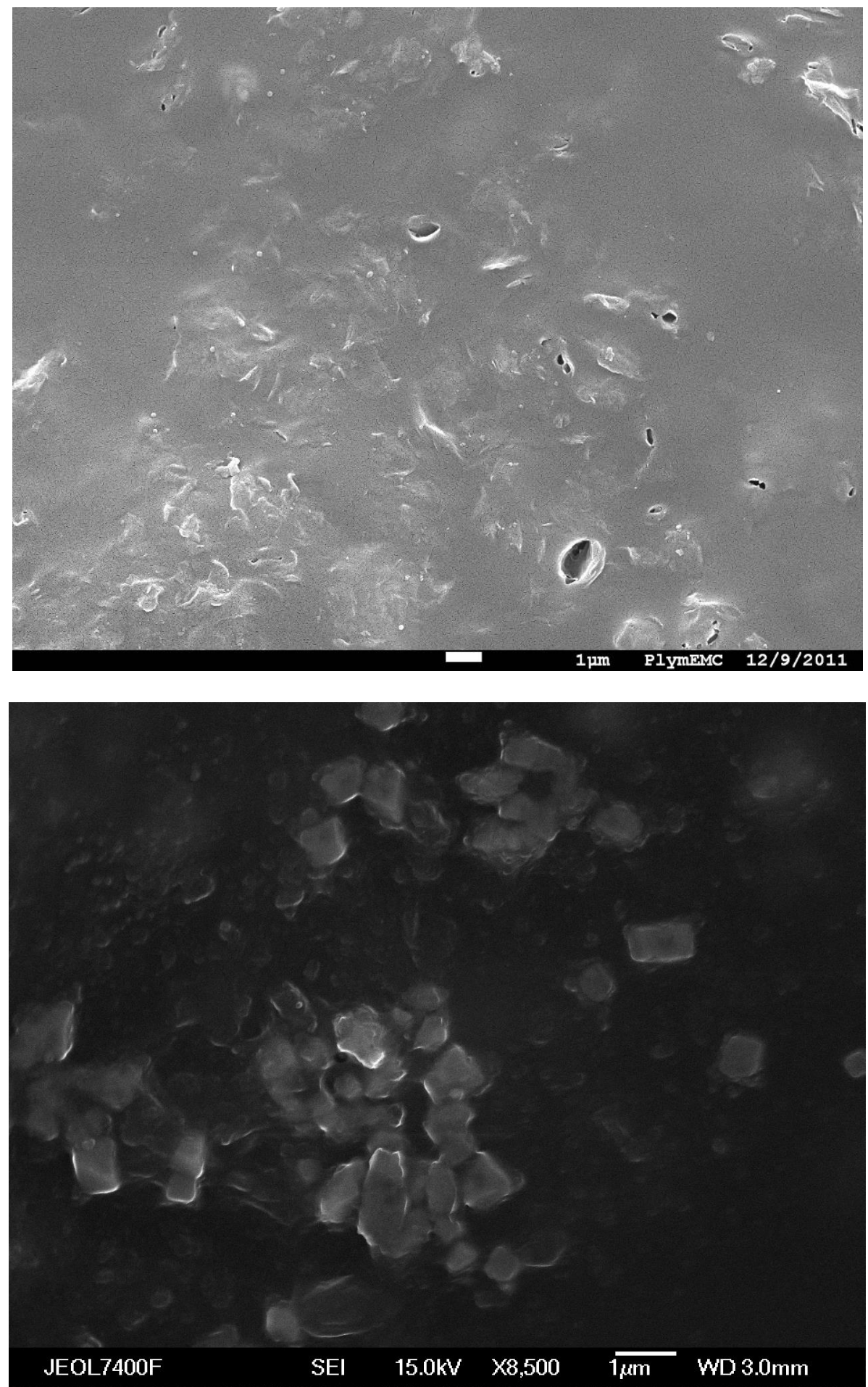

Figure 7(a) Scanning electron microscope images of monolithic polyimide and (b) Scanning electron microscope images clay/polyimide composite coating

\subsection{Adhesion test results}

For each coupon, the adhesion testing was performed at least three times, and the average value was evaluated. Because this is a destructive measurement, the bonding positions had an offset on the 
coupon, as shown in Figure 8. Two different surface condition were tested - one is a bare 13Cr steel (alloy steel with $12-14 \% \mathrm{Cr}$ ) without any coating while the other was coated with a coating named Clear Plate ${ }^{\mathrm{TM}}$ patented by Hunting Inc (UK).

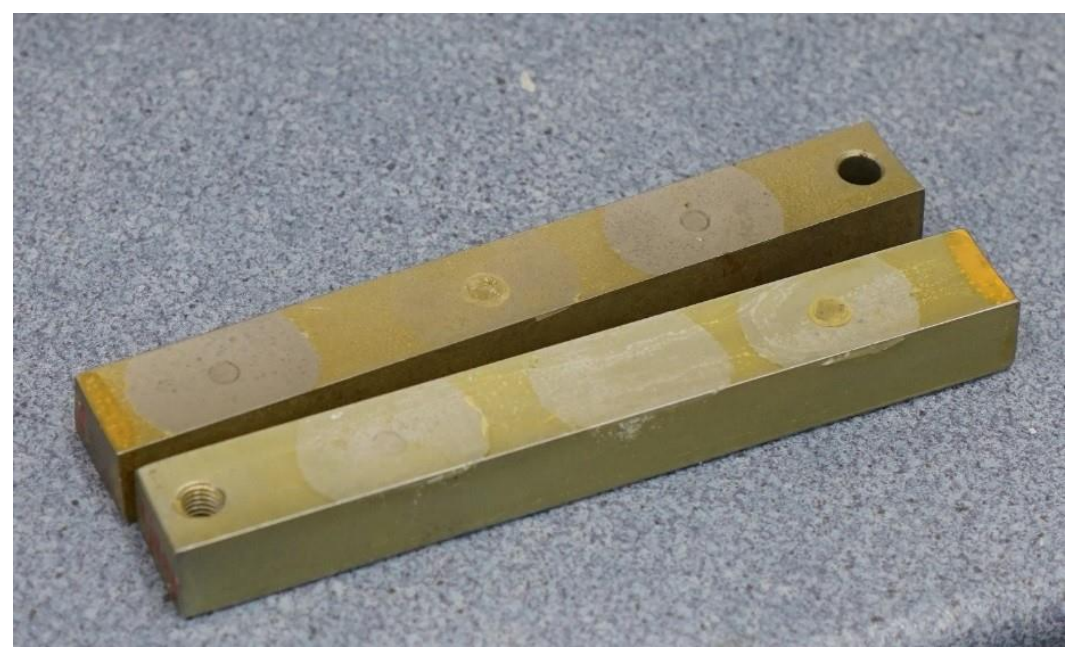

Figure 8 . The debonded coatings after the push-off adhesion testing

Table 1 gives a summary of the adhesion test results, and the coatings were pushed off in all cases. It can be seen from the table that both the two coatings showed quite good adhesion strength with very small deviation, and the Clear Plate ${ }^{\mathrm{TM}}$ generally presented higher bonding strength (almost double that of the $13 \mathrm{Cr}$ steel). It was noted that the composite suspension sticks to the substrate with Clear Plate $^{\mathrm{TM}}$ than the bare $13 \mathrm{Cr}$ steel. This is believed to be responsible for the improved adhesion with Clear Plate ${ }^{\mathrm{TM}}$.

Table 1 Adhesion test results. The standard deviation is also shown in the table.

\begin{tabular}{|l|r|r|r|l|r|}
\hline & $\begin{array}{l}\text { Test1 } \\
\text { (MPa) }\end{array}$ & $\begin{array}{l}\text { Test2 } \\
(\mathrm{MPa})\end{array}$ & $\begin{array}{l}\text { Test3 } \\
(\mathrm{MPa})\end{array}$ & $\begin{array}{l}\text { Average } \\
(\mathrm{MPa})\end{array}$ & $\begin{array}{l}\text { Sdv } \\
(\mathrm{MPa})\end{array}$ \\
\hline Bronze base coat & 10 & 9.6 & 10 & 9.9 & 0.26 \\
\hline $13 \mathrm{Cr}$ & 4.8 & 6.8 & 5.4 & 5.7 & 1 \\
\hline
\end{tabular}

\subsection{Coefficient of friction}

Three cycles were run for each pair of coupons using the test rig described in Section 2.4 (each cycle contained two strokes, '+' for loading and '-' for unloading). The coefficient of friction (COF) is 
plotted as a function of average contact pressure, as shown in Figure 9. Some data near the start and end of each stroke were truncated due to the noise in data. The COF for the whole three sliding cycles fell in range of $0.06-0.14$. This is much smaller than epoxy or epoxy based composite coatings reported by the authors previously [24]. The set of ' $1+$ ' represents the first loading stroke while '1' for the unloading stroke and so on. The COF increased gradually with the increase of normal force (as well as the contact pressure), however this relation was slightly different by increasing the sliding distance (cycle number). It is found that the average COF for individual cycle changes slightly with test cycle. In the first stroke of the first cycle, the normal force was high, however it decreased a bit due to the material wear under the contact pressure, therefore the COF was the highest in the first stroke, and then decreased in the second cycle. Interestingly, the COF started to increase in the third sliding cycle. This is correlated with the increasing wear and damage of the coating material. Figure 10(a) shows the microscopic image of the bottom coupons (nanoclay composite coated), while Figure 10(b) is a magnified image of the previous one. There was a very light scratch imprint on the coating film, indicating very good anti-galling resistance and adhesion strength under significant contact pressure. This wear rate is very low compared to epoxy based coatings previously reported by the author and his collaborators [12]. It is also noted that a small amount of material has been transferred to the counterface.

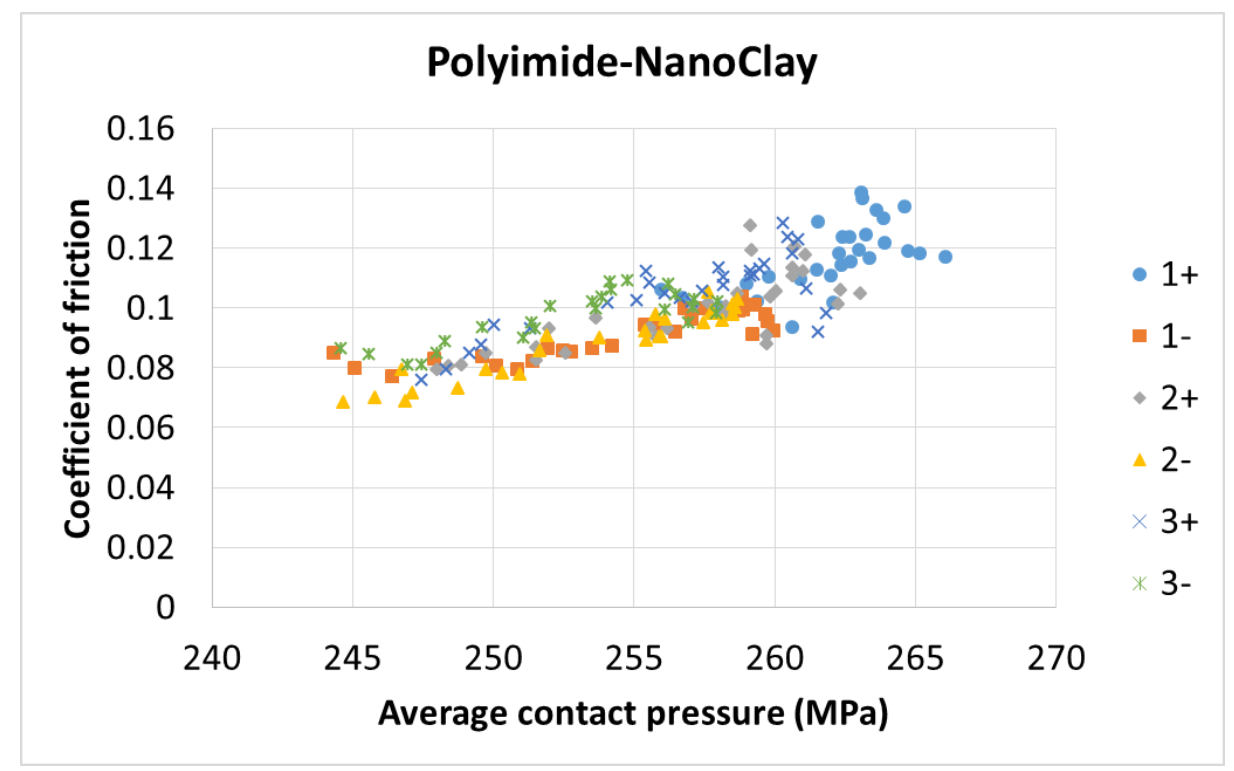

Figure 9. Coefficient of friction in sliding against a shot peened steel 

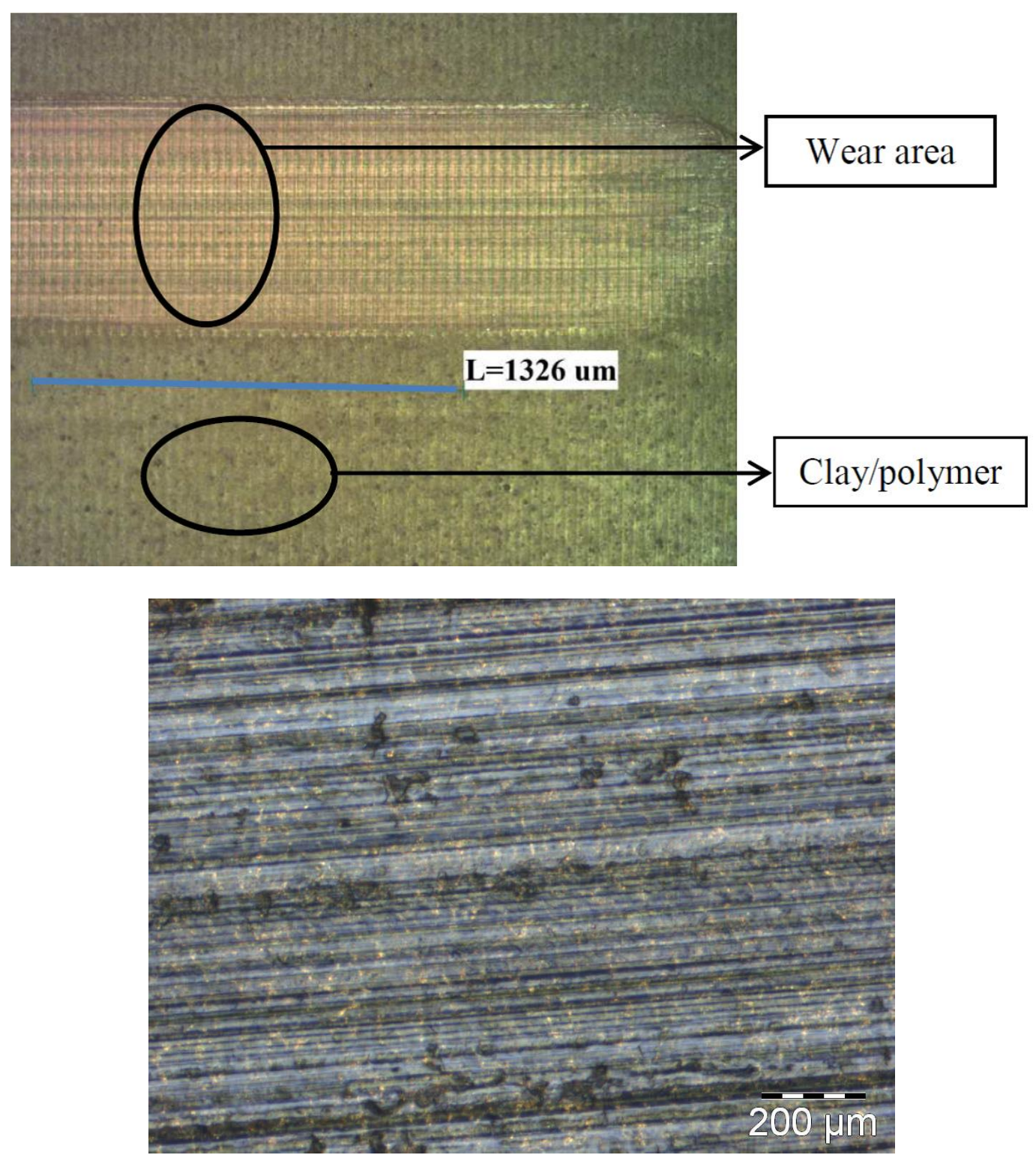

Figure 10. Wear on clay-polyimide composite coating in sliding against a shot peened steel, (a) at low magnification of wear track near maximum normal force, (b) at higher magnification of the wear track.

\section{Conclusions}

The commercially sourced Montmorillonite nanoclay particles were successfully dispersed in polyimide precursors using ammonium salt. The dispersed nanoclay/polyimide composite suspension was coated onto alloy steel coupons for friction and galling tests. The adhesion and sliding test results indicated that the composite coating has good adhesion to alloy steel with Clear Plate ${ }^{\mathrm{TM}}$ coating under significant contact pressure. The improved adhesion strength is owing to improved stiction of the composite to the substrate. The initial coefficient of friction is around 0.08 but increases to 0.15 due 
to wear but stabilizes to 0.1 after the first cycle.

\section{Acknowledgement}

The contribution of Dr R Rothwell to the project is acknowledged. The authors are grateful for the financial support of Innovate UK through a Knowledge Transfer Partnership. The authors are also indebted to the technical support of Engineering Laboratory and Electron Microscope Centre at both Plymouth University and the University of Derby.

\section{References}

1. Chen, R., C.-a. Wang, Y. Huang, et al. An efficient biomimetic process for fabrication of artificial nacre with ordered-nanostructure. Materials Science and Engineering: C.2008, 28: 218-222.

2. Chinn, D., G. R. Deppe, A. M. Helgeson, et al. Process and system for producing synthetic crude oil from offshore produced fluids containing high CO2 content. 2015.

3. Chiu, C.-W., T.-K. Huang, Y.-C. Wang, et al. Intercalation strategies in clay/polymer hybrids. Progress in Polymer Science.2014, 39: 443-485.

4. Clair, A. K. S. and T. L. S. Clair. The development of aerospace polyimide adhesives. Am Chem Soc Div Polym Mater Sci Eng. 1984, 51: 62.

5. Elsner, G., J. Kempf, J. Bartha, et al. Anisotropy of thermal expansion of thin polyimide films. Thin Solid Films. 1990, 185: 189-197.

6. Geffken, R. An Overview of Polyimide Use in Integrated Circuits and Packaging. Proceedings of the Third International Symposium on Ultra Large Scale Integration Science and Technology,1991.

7. Goff, D., E. Yuan and H. Long. HJ Neuhaus in: Polymeric Materials for Electronics Packaging and Interconnection; JH Lupinski, RS Moore (Eds.); Am. Chem. Soc. Symp. Series,1989.

8. Goff, D., E. Yuan, H. Long, et al. Organic dielectric materials with reduced moisture absorption and improved electrical properties. ACS Publications.1989.

9. Hanaor, D. A. H., Y. Gan and I. Einav. Contact mechanics of fractal surfaces by spline assisted discretisation. International Journal of Solids and Structures.2015, 59: 121-131.

10. Jiang, J.-S. and B.-S. Chiou. The effect of polyimide passivation on the electromigration of $\mathrm{Cu}$ multilayer interconnections. Journal of Materials Science: Materials in Electronics.2001, 12: 655659.

11. Khayankarn, O., R. Magaraphan and J. W. Schwank. Adhesion and permeability of polyimideclay nanocomposite films for protective coatings. Journal of applied polymer science.2003, 89: 28752881. 
12. Le, H., A. Howson, M. Ramanauskas, et al. Tribological characterisation of air-sprayed epoxyCNT nanocomposite coatings. Tribology Letters. 2012, 45: 301-308.

13. Le, H., F. Stewart and J. Williams. A Simplified Model of Surface Burnishing and Friction in Repeated Make-Up Process of Premium Tubular Connections. Tribology Letters. 2015, 59: 35.

14. Liaw, D.-J., K.-L. Wang, Y.-C. Huang, et al. Advanced polyimide materials: Syntheses, physical properties and applications. Progress in Polymer Science.2012, 37: 907-974.

15. Meng, M. Effects of marine environment exposure on the static and fatigue mechanical properties of carbon fibre-epoxy composite. PhD thesis.2016.

16. Miller, J. Thermally conductive thermoplastics for die-level packaging of microelectronics. 2006.

17. Mittal, K. L. Polyimides: synthesis, characterization, and applications. Springer Science \& Business Media. 2013.

18. Ohya, H., V. Kudryavsev and S. I. Semenova. Polyimide membranes: applications, fabrications and properties. CRC Press. 1997.

19. Okada, A., M. Kawasumi, A. Usuki, et al. Nylon 6-clay hybrid. Mater Res Soc Proc,1990.

20. Ray, S. S. and M. Okamoto. Polymer/layered silicate nanocomposites: a review from preparation to processing. Progress in Polymer Science.2003, 28: 1539-1641.

21. Sroog, C. and J. Polyimides. Polym Sci Macromol Rev. 1976.

22. Stewart, F., H. Le, J. Williams, et al. Characterisation of friction and lubrication regimes in premium tubular connections. Tribology International.2012, 53: 159-166.

23. Suin, S., S. Maiti, N. K. Shrivastava, et al. Mechanically improved and optically transparent polycarbonate/clay nanocomposites using phosphonium modified organoclay. Materials \& Design (1980-2015).2014, 54: 553-563.

24. Tyan, H. L., K. H. Wei and T. E. Hsieh. Mechanical properties of clay - polyimide (BTDA ODA) nanocomposites via ODA - modified organoclay. Journal of Polymer Science Part B: Polymer Physics.2000, 38: 2873-2878.

25. Wakefield, G. F. Plastic packaging of microelectronic circuit devices. Google Patents.1997.

26. Wang, C.-A., H. Le and Y. Huang. Rapid assembly processes of ordered inorganic/organic nanocomposites. Biomimetics: Learning From Nature. 2010.

27. Weiser, E. S., T. F. Johnson, T. L. St Clair, et al. Polyimide foams for aerospace vehicles. High Performance Polymers.2000, 12: 1-12.

28. Wilson, A. M. Polyimide insulators for multilevel interconnections. Thin Solid Films. 1981, 83: 145-163.

29. Wind, J. D., D. R. Paul and W. J. Koros. Natural gas permeation in polyimide membranes. 
Journal of Membrane Science.2004, 228: 227-236.

30. Wind, J. D., C. Staudt-Bickel, D. R. Paul, et al. The effects of crosslinking chemistry on CO2 plasticization of polyimide gas separation membranes. Industrial \& engineering chemistry research.2002, 41: 6139-6148.

31. Yano, K., A. Usuki, A. Okada, et al. Synthesis and properties of polyimide-clay hybrid. Journal of Polymer Science Part A: Polymer Chemistry. 1993, 31: 2493-2498. 